\title{
REFLECTIONS \\ South African HIV-1 vaccine candidates - the journey from the bench to clinical trials
}

\author{
Anna-Lise Williamson, Ed Rybicki, Enid Shephard, Glenda Gray, Linda-Gail Bekker, Katrina Downing, Carolyn Williamson
}

Around 2.5 million people become infected with human immunodeficiency virus (HIV) each year. This extraordinary toll in human life and public health worldwide will only be reversed with effective prevention. Vaccination is regarded as the most effective way to prevent infectious disease. However, there are many challenges to overcome before a successful prophylactic HIV vaccine will be available.

We are participating in a global effort to develop and test candidate HIV vaccines. Two candidate prophylactic HIV vaccines that were designed and developed at the University of Cape Town (UCT) entered phase 1 clinical trials in the USA and South Africa in 2009, after a 9-year development period. In addition to the vaccines in clinical trial, there is a pipeline of candidate HIV-1 subtype $C$ vaccines including virus-like particles, novel DNA vaccines, capripoxvirus and Bacillus Calmette-Guérin (BCG)-vectored vaccines. This article describes the history of HIV vaccine research at UCT, and the partnerships that made the project possible.

S Afr Med J 2012;102(6):452-455.
As the country with the largest number of infected individuals in the world, South Africa (SA) is at the epicentre of the human immunodeficiency virus (HIV) epidemic. In 2008 there were 5.7 million people living with HIV in SA, accounting for $18 \%$ of the global total, i.e. 1 in 6 people living with HIV in the world today lives in SA. This is in contrast to SA's population size, which is just $0.7 \%$ of the world's total population. ${ }^{1}$ History has taught us that the way to eradicate a global viral epidemic is to design, massproduce, and then systematically vaccinate the population at risk with an effective prophylactic vaccine. Diseases such as smallpox in humans and rinderpest in cattle have been eradicated, and other diseases such as poliomyelitis and tetanus are now rare as a result of vaccination. ${ }^{2}$ Recently, rotavirus vaccination has had a large impact on reducing infant mortality. ${ }^{3}$ Therefore, it is appropriate that a long-term goal of HIV control programmes should include the development of a prophylactic HIV vaccine. However, the past has also shown us that this path to a 'silver bullet' may be a long and complicated one.

In 2009 the University of Cape Town (UCT) announced that 2 candidate prophylactic HIV vaccines, that were designed and developed at the university, had entered phase 1 clinical trials. ${ }^{4}$ This article describes the history of HIV vaccine research at UCT, and the partnerships that made the project possible.

Anna-Lise Williamson and Carolyn Williamson: Institute of Infectious Disease and Molecular Medicine, University of Cape Town (UCT); National Health Laboratory Service, Groote Schuur Hospital; and Division of Medical Virology, Department of Clinical Laboratory Science, UCT. Ed Rybicki and Katrina Downing: Institute of Infectious Disease and Molecular Medicine, UCT. Enid Shephard: South African Medical Research Council (MRC), Tygerberg, and Department of Medicine, UCT. Glenda Gray: Perinatal HIV Research Unit (PHRU), University of the Witwatersrand, Johannesburg. Linda-Gail Bekker: Institute of Infectious Disease and Molecular Medicine, UCT, and MRC, Tygerberg.
Challenges in HIV vaccine development HIV is a highly variable virus, with the sequence diversity in one person being equivalent to that seen in an influenza outbreak in a whole country in 1 year. ${ }^{5}$ Given that new combinations of influenza vaccines are potentially needed each year, this poses a major challenge to the development of an HIV vaccine or vaccines. In addition, animal models for HIV provide useful information but are not perfect: the positive results seen in rhesus macaques with simian immunodeficiency virus (SIV)/simian/human immunodeficiency virus (SHIV) vaccines in terms of protection from challenge have not been translated into human clinical trials. There is therefore a limited understanding of the correlates of protection needed to design an HIV vaccine. In the recent past, HIV vaccines have been designed to induce either good antibody responses or T-cell responses. However, it is likely that an effective prophylactic vaccine will have to induce both types of response: antibody responses are desirable in order to prevent infection, and a good T-cell response to remove infected cells before infection is established is also desirable. A strong early T-cell response should also impact on establishment of the HIV set point if the infection is not eliminated, resulting in slower progression to AIDS.

\section{Indications that a vaccine could work}

To date candidate HIV vaccines have been tested in 3 human efficacy (phase 3) clinical trials. Both the first trial, based on an HIV-1 subtype B envelope protein, and the second trial, based on an adenovirus vector expressing HIV-1 sub-type B Gag, Pol, and Nef proteins, gave no protection from HIV infection. The third trial - RV144, performed in Thailand - gave 60\% protection (post hoc analysis) from HIV infection 1 year after vaccination, and $31.2 \%$ at the end of 3.5 years. ${ }^{6}$ This vaccine is a combination of envelope protein (subtype B and E) and a canary poxvirus vector (ALVACHIV), expressing HIV-1 subtype B protease and Gag, and a fusion subtype E and B envelope. Despite the partial success of the RV144 trial, the correlates of protection have not been easy to establish, and research in this direction is still ongoing. It is likely that protection was antibody-based, but not related to neutralising antibodies.

Requirements for a vaccine programme Vaccine development requires a multidisciplinary team of people to enable the network required to get the vaccine from early concept 
development into clinical trials (Fig. 1). The time-lines for product development are up to 10 years from concept to manufacturing of the vaccine. Resources are needed to keep all components of the network functioning along with a good management structure. It is fortunate that in SA there is a well-developed regulatory framework, as illustrated in Fig. 2. The UCT Vaccine Development Group was involved in the early part of the vaccine pipeline, as well as in producing preclinical data needed for the regulatory bodies (the Food and Drug Administration (FDA), USA, and the Medicines Control Council (MCC), SA). The clinical sites developed both through national funding via the South African AIDS Vaccine Initiative (SAAVI) and international funding, such as the National Institutes of Health (NIH)-funded HIV Vaccine Trials Network (HVTN) and the multinational International AIDS Vaccine Initiative (IAVI), were responsible for providing internationally accredited clinical trial sites

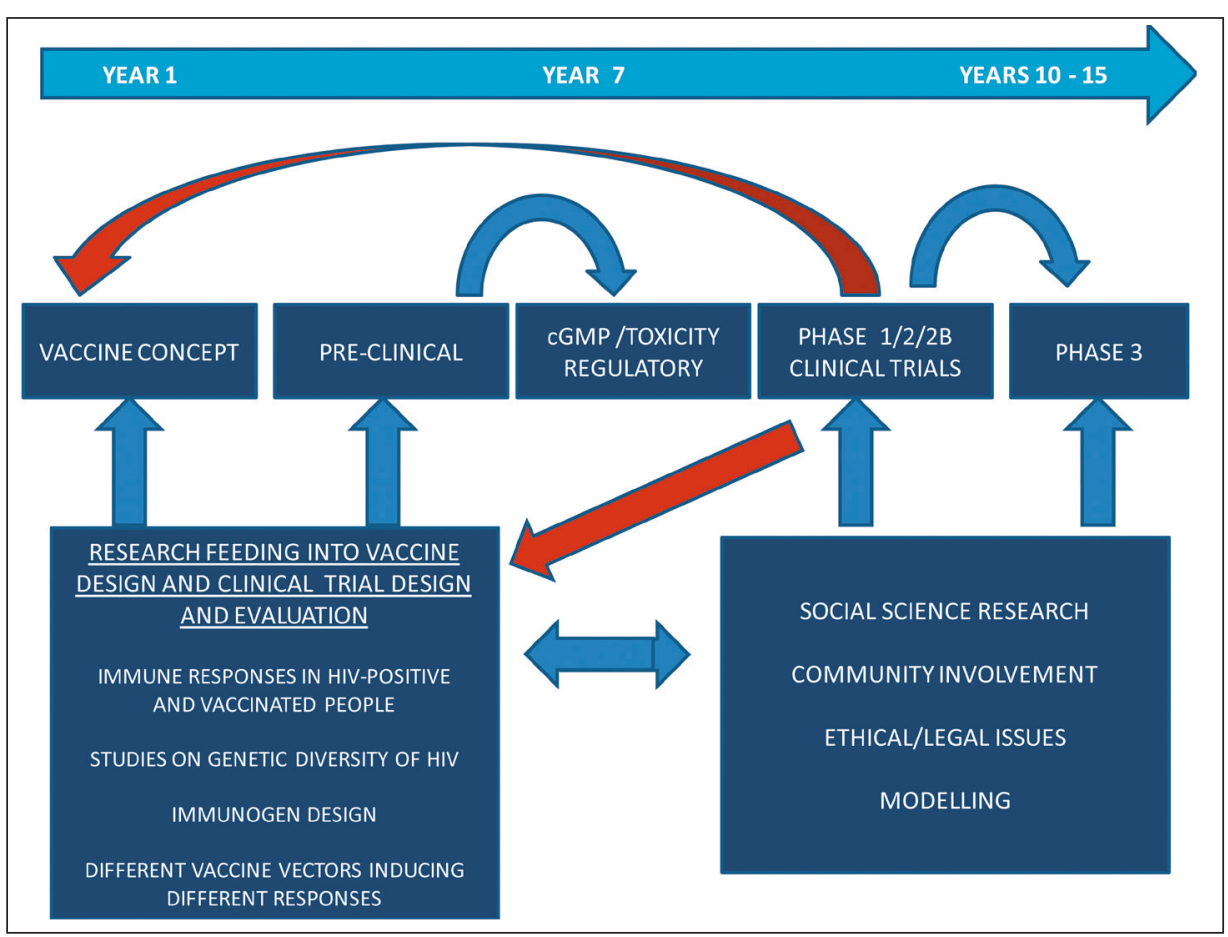

Fig. 1. The time-line for vaccine development and the network required to get the vaccine from early concept development into clinical trials (cGMP = current good manufacturing practice).

\begin{tabular}{|c|c|c|c|}
\hline YEAR 1 & & YEAR 7 & YEARS 10 - 15 \\
\hline VACCINE CONCEPT & PRE-CLINICAL & $\begin{array}{l}\text { cGMP /TOXICITY } \\
\text { REGULATORY }\end{array}$ & $\begin{array}{l}\text { PHASE } 1 / 2 / 2 B \\
\text { CLINICAL TRIALS }\end{array}$ \\
\hline $\begin{array}{l}\text { GMO-REGISTERED } \\
\text { LABORATORY }\end{array}$ & $\begin{array}{l}\text { ANIMAL ETHICS } \\
\text { APPROVAL }\end{array}$ & $\begin{array}{l}\text { CURRENT GOOD } \\
\text { MANUFACTURING } \\
\text { PRACTICE - CGMP } \\
\text { CURRENT GOOD } \\
\text { LABORATORY } \\
\text { PRACTICE - GLP }\end{array}$ & $\begin{array}{l}\text { GMO COUNCIL APPROVAL FOR } \\
\text { CONTAINED RELEASE } \\
\text { MEDICINES CONTROL COUNCIL } \\
\text { APPROVAL } \\
\text { ETHICS APPROVAL LOCAL } \\
\text { COMMITTEE } \\
\text { MONITORING BY DATA AND } \\
\text { SAFETY COMMITTEE } \\
\text { GOOD CLINICAL PRACTICE }\end{array}$ \\
\hline
\end{tabular}

Fig. 2. The regulatory process for moving vaccines from vaccine concept into clinical trials. GMO = genetically modified organism. capable of conducting HIV vaccine trials, from earliest phase through to efficacy, to the highest international standards.

\section{UCT HIV Vaccine Development Group}

In 2000 a UCT-based consortium was awarded funds by SAAVI for the development of HIV-1 subtype C vaccines for SA. The UCT Vaccine Development Group's expertise and previous experience in the development of DNA vaccines, subunit vaccines, poxvirus- and Bacillus Calmette-Guérin (BCG)-based vaccines formed the core of the programme. The group built on this expertise to develop candidate HIV vaccines and to test different prime-boost combinations in non-human primate models. This enabled the development of considerable HIV immunology expertise within the group. SAAVI was reviewed regularly by a distinguished panel of international experts, who advised in 2001 that 2 of the promising candidate vaccines from the UCT programme be selected and fast-tracked to human clinical trial. The programme was then divided into project teams, some for the development of these 2 vaccines for clinical trial and others for the early pipeline vaccine development projects.

\section{Circulating HIV-1 subtypes:} characterisation

Research on virus characterisation in SA had its beginnings in Carolyn Williamson's group in the late 1990s, with the finding that men who have sex with men were predominantly infected with the HIV-1 subtype B virus, the main circulating virus in Europe and the USA. In contrast, the local heterosexual epidemic was mainly HIV-1 subtype C, which reflected the dominant virus subtypes in neighbouring SADC countries. The extent of diversity in HIV made it important to identify the subtypes circulating in the heterosexual epidemic before designing vaccines for the region. A study of recently transmitted viruses in KwaZuluNatal indicated that these were overwhelmingly HIV-1 subtype C. Several isolates were selected on which to base an HIV vaccine; criteria for selection included isolation of the virus within a year of transmission, the ability of the virus to grow in cell culture, the full genome sequence of the virus and the availability of serum. To reduce the difference between the vaccine immunogen and the circulating viruses, a virus isolate selected for the vaccine was closest to the consensus sequence for local subtype $\mathrm{C}$ viruses. ${ }^{7}$

\section{Early pipeline HIV-1 subtype C vaccines}

Researchers at UCT have a history of developing novel viral vaccine 
Table 1. The pipeline of candidate HIV vaccines at the University of Cape Town (shaded area indicates project complete)

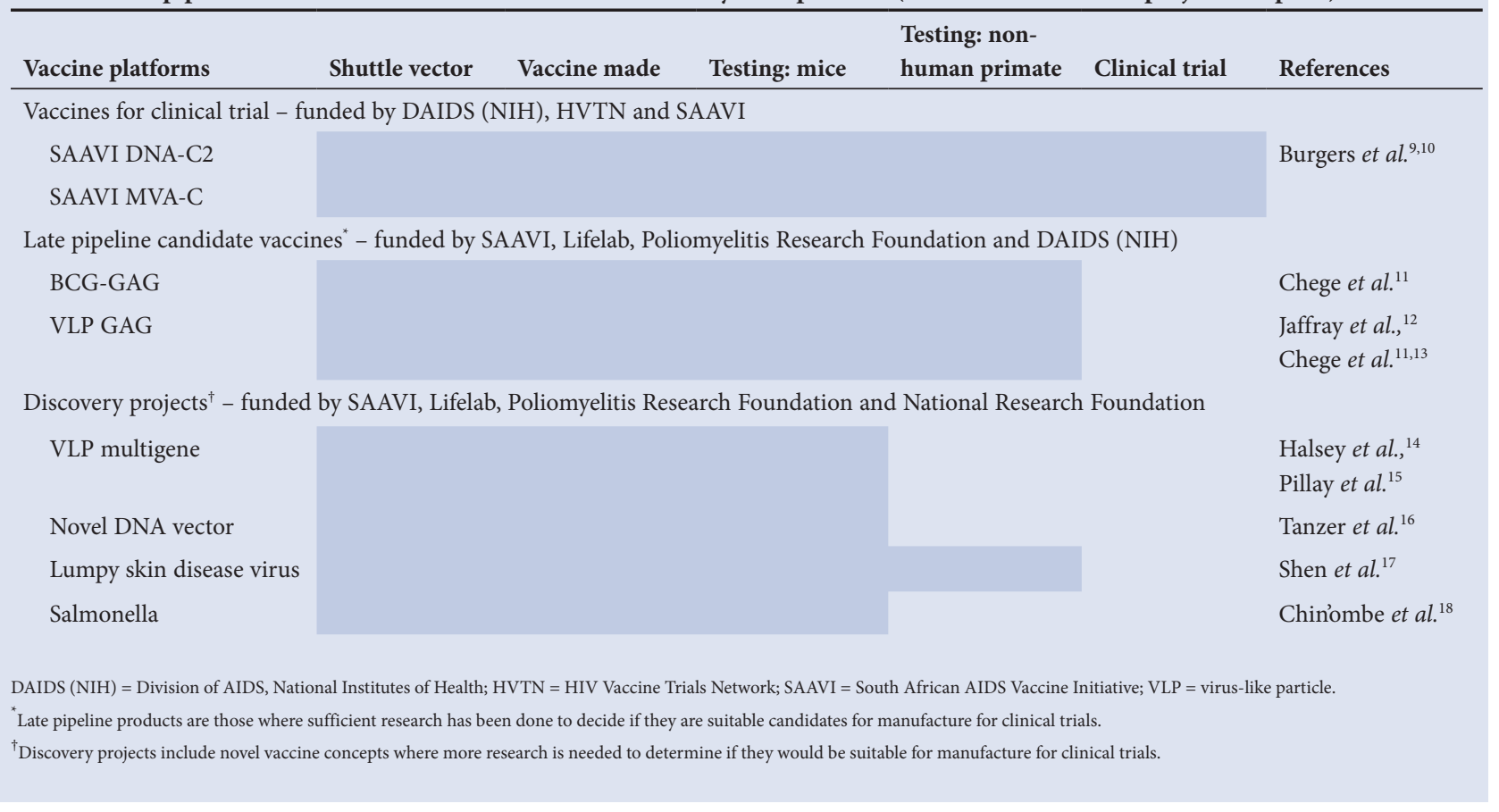

concepts, as illustrated by their work on the BCG vaccine (the vaccine against tuberculosis), expressing papillomavirus or rotavirus proteins, as well as the extensive plant and insect cell production of subunit vaccines and poxvirus-based vaccines.

Strategies were thus devised to construct novel HIV candidate vaccines based on local HIV isolates. Table 1 gives a summary of the candidate HIV vaccines developed at UCT. The vaccines were produced in the laboratory, and after quality assessment, candidates were selected for preliminary immunogenicity testing in mice. Vaccine regimens involved heterologous prime-boost combinations, as this has been shown to result in better T-cell responses to HIV compared with homologous prime-boost strategies. ${ }^{8}$ Antibody responses were also monitored. After demonstrating adequate immune response in mice, the vaccines were tested in non-human primates at the Medical Research Council (MRC) non-human primate facility, given the far closer genetic relationship between primates and humans. (The MRC has for many years had a non-human primate facility which, in the early years, included baboons, because of availability; more recently rhesus macaques became available after SAAVI purchased a breeding colony. This facility is an extremely valuable resource for HIV and other vaccine research in SA.)

A number of other novel platforms were established for the production of subunit vaccines, including tobacco ${ }^{19}$ and recombinant baculovirus/insect cell platforms. ${ }^{12}$ Development of plant-based subunit vaccines, although successful, was stopped as a result of low yields, and replaced with insect cell produced virus-like particle vaccine candidates (VLPs). The group investigated fusion proteins based on Gag, ${ }^{14}$ and subsequently the optimising of production parameters and testing of immunogenicity of Gag-RT and Gag-Tat-Nef fusion VLPs. ${ }^{15}$

Novel HIV vaccine vectors were also explored, with an enhanced experimental DNA vaccine for HIV being made that utilises an expression enhancer derived from an animal circovirus. ${ }^{16}$ A novel HIV vaccine was made based on the cattle lumpy skin disease capripoxvirus vaccine. ${ }^{17}$ BCG was investigated as a vaccine vector, and induced good priming immune responses in mice and nonhuman primates. ${ }^{15}$ Salmonella was tested as an HIV vaccine vector in mice. ${ }^{18} \mathrm{HIV}$ VLPs were particularly successful at boosting HIV immune responses in baboons induced by priming with either DNA vaccines $^{11}$ or BCG-based vaccines. ${ }^{13}$

\section{Vaccines for clinical trial}

Two HIV vaccines, designated SAAVI DNA-C2 and SAAVI MVA-C, were deemed suitable for human clinical trials. This was a challenging project, because of cost and relative local inexperience in HIV vaccine development. The project was done in close partnership with the $\mathrm{NIH}$ in the USA. The NIH funded important components of the programme, including manufacture and toxicity testing of both vaccines in the USA, as capacity was not available in SA. Vaccines needed to be manufactured according to current good manufacturing practice (GMP) principles, with demonstrably limited toxicity in rabbit tests. The NIH also funded the regulatory documentation, a vital part of the approval process. Significant mentoring from people at the NIH enabled the programme to move forward and to build local capacity to support HIV vaccine development. Finally, the HVTN, which has established clinical trial sites globally and in SA, funded the clinical trials in the USA and SA. ${ }^{4}$

SAAVI DNA-C2 was based on a mixture of 2 DNA plasmids. One plasmid expressed a polyprotein designated Grttn, consisting of translational fusions of HIV-1 subtype C Gag, reverse transcriptase, Tat and Nef. All the sequences were codon optimised for high levels of expression, as well as being modified to ensure that they were safe in humans. ${ }^{20}$ The second plasmid expressed an HIV-1 subtype $\mathrm{C}$ truncated envelope protein (Env, gp150). The second vaccine, SAAVI MVA-C, was based on a modified version of the smallpox virus vaccine called modified vaccinia Ankara (MVA), and had matching HIV genes to SAAVI DNA-C2. These vaccines were extensively characterised at UCT by means of expression studies, investigations of potency and stability, and mouse and non-human primate immunogenicity studies. ${ }^{9,10}$ In order to monitor the potency of SAAVI DNA-C2 during a clinical trial, a laboratory compliant with the Organisation for Economic Co-operation and Development (OECD) principles of good laboratory practice (GLP) was established, the only one in an academic setting in SA. 
Clinical trials for testing UCT-developed vaccines

The first phase I placebo-controlled clinical trial on SAAVI vaccines (approved by the FDA, the MCC, Genetically Modified Organisms Act Executive Council, Division of AIDS, NIH and local research ethics committees) has been undertaken. The trial, called HVTN 073/SAAVI 102, was to evaluate the safety and immunogenicity of SAAVI DNA-C2 vaccine boosted by SAAVI MVA-C vaccine in HIV-uninfected healthy vaccinia-naïve adult participants in SA and the USA. Forty-eight participants (12 USA, 18 at each of the Cape Town and Soweto sites) were randomised to receive either vaccine $(n=40)$ or placebo $(n=8)$. Participants received 3 doses intramuscularly (IM) of $4 \mathrm{mg}$ of SAAVI DNA-C2 or placebo 28 days apart, and 2 doses IM of SAAVI MVA-C at $1.45 \times 10^{9}$ plaque-forming units or placebo at 112 days and 140 days after the first vaccination. Immunogenicity endpoints were measured at days 126 and $154(2$ weeks following the first and second MVA vaccinations). HIV-1 specific CD4+ and CD8+ T-cell responses were measured using a validated intracellular cytokine staining (ICS) assay. The vaccine regimen was found to be safe and well tolerated. Vaccination with this set of HIV vaccines elicited high CD4+ responses and modest CD8+ responses. USA participants had an $80 \%$ overall CD4+ response rate compared with $64 \%$ seen in South Africans. For CD8+ T-cells expressing interleukin-2 (IL-2) or interferon-gamma (IFN- $\gamma$ ), the overall response rate at 126 days was $14 \%$ (USA $30 \%$, SA $8 \%$ ); which increased to $33 \%$ at 154 days (USA 50\%, SA 29\%) after the second MVA vaccination. ${ }^{21}$ These data are consistent with other prime-boost regimens of DNA and MVA, and suggested further study of these subtype $C$ immunogens was warranted. Based on the above responses, a study extension was proposed and approved in 2011, following the promising results of the RV144 trial which will add a protein boost of subtype C gp140 with MF59 (Novartis) to the DNA/MVA prime-boost regimen in this study. In addition, SAAVI DNA-C2, SAAVI MVA-C and Novartis subtype C gp140 with MF59 adjuvant in another phase 1 study, HVTN 086/SAAVI 103 was approved and commenced enrolment at the end of 2011.

\section{Conclusions}

Two candidate HIV vaccines have successfully been taken from basic research concepts through to phase 1 clinical trial. This required the establishment of a sophisticated laboratory infrastructure and skillsets for the preclinical part of the programme, and the exploitation of various networks and of different sets of expertise to successfully move the product into clinical trial. In addition a number of other candidate HIV vaccines have been developed. The considerable expertise and experience gained during the HIV vaccine development programme can be used to develop other candidate vaccines in future.

This research represents possibly the best example of a multidisciplinary research effort taking a project from the basic concept through to clinical trial in Africa. It shows that academic institutions in SA have the capacity to undertake these projects, and contribute meaningfully to the global initiative to make a successful prophylactic HIV vaccine.

Acknowledgements. UCT vaccine developers: Anna-Lise Williamson, Carolyn Williamson; UCT pre-clinical team members: Anna-Lise Williamson, Carolyn Williamson, Katrina Downing, Enid Shephard, Etienne Hurter, Wendy Burgers, Fiona Tanzer, Gerald Chege, Anke Binde, Jolanda Truter, Craig Adams, Shireen Galant, Desiree Bowers, Rodney Lucas, Zaahier Isaacs, Tracy Blanckensee, Tracey Muller, Evelyn Majapelo, Sandhya Miseer, Jo van Harmelen, Prisca Mbele, Lindi Roberts; SAAVI development team: Elise Levendal (SAAVI), Carolyn Williamson (UCT),
Anna-Lise Williamson (UCT), Enid Shephard (UCT), Katrina Downing (UCT), Wendy Burgers (UCT), Clive Gray (NICD), Glenda Gray (PHRU, Wits), Lynn Morris (NICD), Lizeka Xiphu (SAAVI); HVTN sponsored clinical trial: Glenda Gray (PI/chair of Clinical Trial, Wits), Kenneth Mayer (co-chair, Fenway), Guy de Bruyn (Wits), Tebego Mogapane (Wits), Linda-Gail Bekker (UCT), Surita Roux (UCT), Marnie Elizaga (HVTN), Steve de Rosa (HVTN), Niles Eaton (HVTN), Clive Gray (NICD), Lynn Morris (NICD); Division of AIDS, NIH, USA: Chris Butler, Michael Pensiero, Becky Sheets, Mary Allen; SRI, USA: Joan Roelands; ABL Inc, USA: Jim Richardson, R Johnson-Leva, Deborah Deane; vaccine manufacturers: Althea Technologies, Inc. (San Diego, USA), Therion Biologics (Boston, USA); UCT vaccine pipeline: Ed Rybicki, Anna-Lise Williamson, Ann Meyers, Gerald Chege, Nicola Douglass, Ros Chapman, Helen Stutz, Will Bourn, Nyasha Chin'ombe, Robin Thomas. We thank the South African AIDS Vaccine Initiative, NIH, HIV Vaccine Trials Network, LifeLab, Poliomyelitis Research Foundation and National Research Foundation for financial support of this project. We thank the MRC for access to the non-human primate facility at Delft.

1. UNAIDS. Report on the global AIDS epidemic 2010. http://www unaids.org/documents/20101123 globalreport_em.pdf (accessed February 2012).

Morens DM, Holmes EC, Davis AS, Taubenberger JK. Global rinderpest eradication: lessons learned and why humans should celebrate too. J Infect Dis 2011;204(4):502-505. [http://dx.doi.org/10.1093/infdis/jir327]

Madhi SA, Cunliffe NA, Steele D, et al. Effect of human rotavirus vaccine on severe diarrhea in African infants. N Engl J Med 2010;362(4):289-298. [http://dx.doi.org/10.1056/NEJMoa0904797]

4. Ncayiyana DJ. SAAVI HIV vaccine trials - one small step for humankind. S Afr Med J 2009;99(10):683

5. Korber B, Gaschen B, Yusim K, Thakallapally R, Kesmir C, Detours V. Evolutionary and immunological implications of contemporary HIV-1 variation. Br Med Bull 2001;58:19-42.

Kim JH, Rerks-Ngarm S, Excler IL, Michael NL. HIV vaccines: lessons learned and the way forward. Curr Opin HIV AIDS 2010;5(5):428-434. [http://dx.doi.org/10.1097/COH]

Williamson C, Morris L, Maughan MF, et al. Characterization and selection of HIV-1 subtype C isolates for use in vaccine development. AIDS Res Hum Retroviruses 2003;19(2):133-144. [http:// dx.doi.org/10.1089/088922203762688649]

8. Newman MI. Heterologous prime-boost vaccination strategies for HIV-1: augmenting cellular Newman M). Heterologous prime-boost vaccination strategies
immune responses. Curr Opin Investig Drugs 2002;3(3):374-378.

. Burgers WA, Chege GK, Muller TL, et al. Broad, high-magnitude and multifunctional CD4+ and Burgers WA, Chege GK, Muller TL, et al. Broad, high-magnitude and multifunctional $\mathrm{CD} 4+$ and
CD8+ T-cell responses elicited by a DNA and modified vaccinia Ankara vaccine containing human CD8+ T-cell responses elicited by a DNA and modified vaccinia Ankara vaccine containing human
immunodeficiency virus type 1 subtype C genes in baboons. J Gen Virol 2009;90(Pt 2):468-480. [http://dx.doi.org/10.1099/vir.0.004614-0]

10. Burgers WA, Shephard E, Monroe JE, et al. Construction, characterization, and immunogenicity of a multigene modified vaccinia Ankara (MVA) vaccine based on HIV type 1 subtype C. AIDS Res Hum Retroviruses 2008;24(2):195-206. [http://dx.doi.org/10.1089/aid.2007.0205]

11. Chege GK, Shephard EG, Meyers A, et al. HIV-1 subtype C Pr55gag virus-like particle vaccine efficiently boosts baboons primed with a matched DNA vaccine. J Gen Virol 2008;89(Pt 9):2214-2227. [http://dx.doi.org/10.1099/vir.0.83501-0]

12. Jaffray A, Shephard E, van Harmelen JH, Williamson C, Williamson AL, Rybicki EP. Human immunodeficiency virus type 1 subtype C Gag virus-like particle boost substantially improves the immune response to a subtype C gag DNA vaccine in mice. J Gen Virol 2004;85(Pt 2):409-413.

13. Chege GK, Thomas R, Shephard EG, et al. A prime-boost immunisation regimen using recombinan BCG and Pr55(gag) virus-like particle vaccines based on HIV type 1 subtype C successfully elicits BCG and Pr55(gag) virus-like particle vaccines based on HIV type 1 subtype C successfully elicits
Gag-specific responses in baboons. Vaccine 2009;27(35):4857-4866. [http://dx.doi.org/10.1016/j.

14. Halsey RJ, Tanzer FL, Meyers A, et al. Chimaeric HIV-1 subtype C Gag molecules with large in-frame C-terminal polypeptide fusions form virus-like particles. Virus Res 2008;133(2):259-268. [http:// dx.doi.org/10.1016/j.virusres.2008.01.012]

15. Pillay S, Shephard EG, Meyers AE, Williamson AL, Rybicki EP. HIV-1 sub-type C chimaeric VLPs boost cellular immune responses in mice. J Immune Based Ther Vaccines 2010;8:7. [http://dx.doi org/10.1186/1476-8518-8-7]

6. Tanzer FL, Shephard EG, Palmer KE, Burger M, Williamson AL, Rybicki EP. The porcine circovirus type 1 capsid gene promoter improves antigen expression and immunogenicity in a HIV-1 plasmid vaccine. Virol J 2011;8(1):51. [http://dx.doi.org/10.1186/1743-422X-8-51]

17. Shen YJ, Shephard E, Douglass N, et al. A novel candidate HIV vaccine vector based on the replication deficient capripoxvirus, lumpy skin disease virus (LSDV). Virol J 2011;8:265. [http://dx.doi. org/10.1186/1743-422X-8-265]

18. Chinombe N, Bourn WR, Williamson AL, Shephard EG. Oral vaccination with a recombinan Salmonella vaccine vector provokes systemic HIV-1 subtype C Gag-specific CD4+ Th1 and Th2 cell immune responses in mice. Virol J 2009;6:87. [http://dx.doi.org/10.1186/1743-422X-6-87]

19. Meyers A, Chakauya E, Shephard E, et al. Expression of HIV-1 antigens in plants as potential subunit Meyers A, Chakauya E, Shephard E, et al. Expression of HIV-1 antigens in plants as
vaccines. BMC Biotechnol 2008;8:53. [http://dx.doi.org/10.1186/1472-6750-8-53]

20. Burgers WA, van Harmelen JH, Shephard E, et al. Design and preclinical evaluation of a multigene human immunodeficiency virus type 1 subtype C DNA vaccine for clinical trial. J Gen Virol 2006;87(Pt 2):399-410. [http://dx.doi.org/10.1099/vir.0.81379-0]

21. Gray G, Elizaga M, Bekker LG, et al. Immunogenicity of a Subtype C HIV Vaccine Regimen, the SAAVI DNA-C2 Vaccine Boosted by SAAVI MVA-C Vaccine: Results of a Phase I Study Conducted in South Africa and USA Amongst HIV Uninfected Adults (HVTN 073/ SAAVI 102). Conference on Retroviruses and Opportunistic Infections (CROI) 2011, Boston, USA 